\title{
The Effect of Teaching Interlanguage Pragmatics on Interpretation Ability of Iranian Translation Students
}

\author{
Mahnaz Mahmoudi Ravesh \\ Department of English, Islamic Azad University, Isfahan (Khorasgan) Branch, Iran \\ E-mail:m.mahmoudi6993@yahoo.com \\ Hossein Heidari Tabrizi (Corresponding author) \\ Department of English, Islamic Azad University, Isfahan (Khorasgan) Branch, Iran \\ E-mail: heidaritabrizi@gmail.com
}

Doi:10.7575/aiac.alls.v.8n.3p.44

URL: http://dx.doi.org/10.7575/aiac.alls.v.8n.3p.44
Received: 18/03/2017

Accepted: 29/05/2017

\begin{abstract}
The present study sought to investigate whether Iranian translation students were successful in comprehending interlanguage pragmatic (ILP) features. Moreover, it tried to figure out whether teaching interlanguage pragmatics proved helpful for the improvement of interpretation ability of Iranian translation students. To this end, 30 students of undergraduate translation studying at Islamic Azad University, Isfahan (Khorasgan) Branch, were chosen to participate in the study. Then, they were divided into two groups of control and experimental. The Oxford Placement Test (OPT) was used to measure the participants' language proficiency. Then, a Discourse Completion Test was administered to measure the participants' interlanguage pragmatics. Using the SPSS 20 software, the ANCOVA and $t$ test were run for the data obtained from both the pre-test and the post-test. The results revealed that ILP features are lacking in the university context. Furthermore, it was shown that ILP features were effective for improving Iranian students' interpretation ability. In this sense, university professors can pay attention to this finding and, where required, they can incorporate ILP features into their courses so as to make attempts to render a more effective learning and teaching environment.
\end{abstract}

Keywords: Interlanguage Pragmatics, Interpretation Course, Iranian Translation Students, Pragmatics

\section{Introduction}

\subsection{Interpreting and Translating}

Interpreting and translating are two closely related linguistic disciplines though they are hardly ever performed by the same people. The difference in skills, training, aptitude and language knowledge are substantial that few people can do both successfully on a professional level. On the surface, the difference between interpreting and translation is only the difference in the medium. It means that, a translator interprets written text while the interpreter translates orally. Both interpreting and translation presuppose a certain love of language and deep knowledge of more than one language (Language Scientific Translation Services).

By interpreting ability in the present study, it is meant the extent to which learners are able to interpret online translation of what they are given. This ability was what BA students of translation are supposed to acquire in a course named "interpretation" in their BA course. They cover the course which is a 2-unit course. At the end of the course students are expected to be able to comprehend a spoken file and deliver a reasonable peace of oral translation correctly.

\subsection{Pragmatic Competence and Interlanguage Pragmatics}

Pragmatic competence is considered as one of the two main components of language competence parallel to organizational competence. The rationale behind the introduction of Interlanguage Pragmatics lies in research conducted by Vygotsky (1978) who made attempts to bring the role of construction of knowledge within society and culture rather than the notion that it is what happens within individuals in solitude. Human knowledge is socially constructed and culturally mediated. He framed his ideas regarding moving learning into Socio-cultural Theory and this theory emphasizes the important role of social interaction in the construction of knowledge.

'Pragmatics' is a branch of linguistics concerned with the use of language in social contexts and the ways people produce and comprehend meanings through language. The term pragmatics was coined in the 1930s by the philosopher C.W. Morris. Subsequently, pragmatics was developed as a subfield of linguistics in the 1970s. At first, pragmatics focused on conversational implicatures, a process through which the speaker implies and a listener infers. Simply put, pragmatics deals with language that is not directly spoken. Instead, the speaker hints at or suggests a meaning, and the listener assumes the correct intention. In a sense, pragmatics is looked as an understanding between people to obey certain rules of interaction. In everyday language, the meanings of words and phrases are not explicitly stated but 
constantly implied and. In certain situations, words can have a certain meaning. Pragmatics studies how words can be interpreted in different ways based on the situation. In addition, it is worth mentioning that in the present study interlanguage in the present means decoding the idea of source language into interlanguage and then from interlanguage into target language.

Interlanguage is a term for a dynamic linguistic system which is developed by a learner of a second language who has not reached proficiency. A learner's interlanguage keeps some features of their first language, and can also overgeneralize some L2 writing and speaking rules. These features of an interlanguage result in the system's unique linguistic organization. Moreover, an interlanguage is based on the learners' experiences with a second language. It can "fossilize", or discontinue developing, in each of the stages. The interlanguage rules are said to be shaped by several factors, including L1-transfer, past learning strategies, strategies of a second language acquisition, L2 communication strategies and overgeneralization of L2 language patterns.

\subsection{Interlanguage Pragmatics and SLA}

Regarding application of interlanguage pragmatics into educational contexts, it is worth mentioning that many studies have taken account of this. This gains more significance due to the fact that language teaching cannot deviate from the progress of each breakthrough and development of the theory of language, interlanguage pragmatics being one of these studies. As a new interdisciplinary branch of study based on the theories of pragmatics, Interlanguage pragmatics is very practical for educational contexts, so theoretical model of interlanguage pragmatics brings about a lot of enlightenment for translation teaching.

It should be noted that inclusion of interlanguage teaching into classroom can precede many problems and difficulties. In this sense, concerning teaching pragmatics and pragmatic competence, some scholars have come up with a number of difficulties teachers might face when attempting to transfer pragmatic teaching into practice. For example, Matsuda (1999) proposed two reasons for the reluctance of pragmatics teaching. Firstly, teaching pragmatics is a difficult and sensitive issue due to high degree of 'face threat' it often involves and, second, the number of available pedagogical resources is limited. However, as he noted somewhere else the reluctance should also be attributed to the lack of some valid methods for testing interlanguage pragmatics.

In addition, teachers can give appropriate feedback after checking out learner's interlanguage. Learners need not worry so much about making mistakes. They can assume that making mistakes is a procedure of development from mother tongue to learning a Second Language. The teachers need to take account this interlanguage pragmatics since without it might be difficult to recognize learners' difficulties and to see what errors they have and in what respects they fall incompetent when using a second language. Furthermore, the notion gains more importance since such errors are considered a reflection of the students' current language system and therefore an authentic aspect of learning process, teachers could now employ activities which do not call for constant supervision of the student's language. Appropriate strategies to be employed in the classroom, such as group work and pair work, can be suitable means for language learning.

\section{Literature Review}

\subsection{Definition and Explanation of ILP}

'Pragmatics' is usually referred to as interlanguage pragmatics (ILP) and is often deemed as a domain within L2 studies, as analogy with interlanguage grammar, interlanguage phonology, and interlanguage lexicon (Kasper \& Rose, 2002). Kasper and Blum-Kulka (1993) define ILP as "the study of non-native speaker's use and acquisition of linguistic action patterns in a second language" (p. 24). They also offer a broader definition of ILP. They argue that "tying interlanguage pragmatics to non-native speakers, or language learners may narrow its scope too restrictively" (p. 3), and include into ILP "the study of intercultural styles brought about through language contact, the conditions for their emergence and change, the relationship to their substrata, and their communicative effectiveness" (p. 4).

In this respect, some teaching practitioners have demonstrated a reluctance in using interlanguage pragmatics into their experiences. This is also approved in Jianda (2007) where he puts that the hesitation in teaching pragmatics could be partly attributed to the lack of some valid methods for testing interlanguage pragmatic knowledge and more studies need to be done to validate methods for pragmatics assessment. In this sense researchers have been attempting to propose methods and strategies for the utilization of interlanguage pragmatics within educational contexts, particularly English as a Foreign Language (EFL) contexts (Brjandi \& Rezaei, 2013; Jianda, 2007).

Neddar (2012) states two difficulties in so doing. The first problem is to decide on the pragmatic systems to be taught. The dominance of English all over the world has not only given rise to several English but also made the notion of native speaker redundant/obsolete. The second difficulty that puts constraints on the teaching of pragmatics has to do with testing. Indeed, the absence of valid testing methods is a crucial argument that is given by some teachers.

'Interlanguage' was coined by Selinker (1972) to refer to the systematic knowledge of an L2 which depends on both these learner's L1 and the target language. The term can have three meanings: (a) to refer to the series of interlocking systems which characterize acquisition, (b) to refer to the system that is observed at a single stage of development ('an interlanguage'), and (c) to refer to particular combinations of source and target languages. He continued, the various shapes of learners' language competence are called interlanguage. The term draws attention to the fact that the learners' language system is neither that of his mother tongue nor that of the second language, but contains elements of both. Therefore, errors need not be seen as signs of failure only, but as evidence of the learner's developing system (p. 96). 
A bulk of studies have so far probed into the effects of interlanguage pragmatics on L2 learning and teaching. Most of these studies have been carried out in educational contexts so as to improve teaching and learning practices. In this respect, some researchers have made attempts to see whether teachers make use of instructions, methods and approaches to teach interlanguage pragmatics. One of these studies which was carried out in an Iranian educational context is Farashaiyan, Tan and Subakir (2014) who sought to investigate the teaching techniques and methods that instructors of Iranian EFL institutes utilized for the instruction of interlanguage pragmatics in their EFL classes. The study employed 238 instructors from institutes of Shiraz, Iran. Use was made of questionnaire and 20 volunteer teachers were invited to answer to questions of a semi-structured interview.

Findings indicated that instructors mostly made use of implicit instruction of pragmatic rules with inductive approach, role-playing, pair-work or group-work, field-experience, topics and situations to teach interlanguage pragmatics. However, they less often utilized explicit teaching of pragmatic features (explanation of politeness matters, pragmatic strategies and so on) with deductive approach, computer programs, films, email exchanges, awareness-raising and production tasks, form-focused teaching, etc. In the same vein, Huang (2010) carried out an investigation with the title of "Interlanguage pragmatics theory and its implications for foreign language" where he described research on theoretical models of Interlanguage Pragmatics and second language acquisition theory mode. Further, he explored these theoretical models of the Foreign Language Teaching. Exploring theories related to Pragmatics and SLA theories together he came to strategies which could serve as the basis for an efficient practice of foreign language teaching.

It is very important to devise strategies and methods to take ILP into teaching and learning contexts. In this sense, learners would become capable of applying pragmatics into their learning experiences and gain proficiency in their pragmatic understanding. For example, Jianda (2002) delineated the importance of teaching pragmatic knowledge to Chinese EFL learners in classrooms. He also discusses pedagogical implications and applications for foreign language teachers and testers. The paper concludes with the suggestion that EFL teachers should teach pragmatic knowledge in class. They also should include interlanguage pragmatic knowledge in large-scale tests.

\subsection{Measuring ILP}

Now that different methods on how to incorporate the pragmatic features into educational background have been noticed, it is important to pay attention to aspects of measuring these strategies, that is to evaluate whether such features are appropriate for the aims they were designed for or not. In this regard, researchers in this field have now and then developed methods for testing pragmatic knowledge. Birjandi and Rezaee (2010), Jianda (2007), Rezaei, Chiew, \& Lee (2014) took account of this in their research. For instance, Birjandi and Rezaei (2010) developed a Multiple-choice Discourse Completion Test (MDCT) to assess the pragmatic knowledge of Iranian EFL learners in relation to the speech acts of request and apology in EFL classrooms. The development process involved several steps.

Neddar (2012) alerts about care that must be taken when trying to design and administer tests of interlanguage pragmatics. As he cites "all testing material cannot be designed without reference to the norms of the NS culture. There appears to be no alternative to the standard of the NS variety. A better standard, if any, has yet to emerge" (p. 5690). Meanwhile, he recommends that studies are necessary to investigate the variability of NSs and the effect of this variability on testing pragmatic competence as a whole. Another point which is crucial when testing this competence, and which he deems as specific to Algeria and most probably to other countries where English has the official status of a second foreign language.

\subsection{Studies Conducted on ILP in the World}

Cai and Wang (2013) made a more comprehensive review of the recent research on Interlanguage pragmatics in Second Language Acquisition, and then they selected the research which focuses on learning process. They presented them into four groups: cross-sectional studies, longitudinal studies, research about pragmatic transfer, and instructed learning of L2 pragmatics. Next their research put forward some research questions for further study, which might lead the researchers to obtain more practical information for promoting L2 pragmatics.

In their review they reported that most studies of ILP focus on second language use, rather than second language learning (Kasper, 1992; cited in Cai \& Wang, 2013). They concluded that they can present the language using condition, but failed to show the language acquiring process. They are not really linked with SLA, but they are useful for exploring the real situation of L2 learners' knowledge or competence of Interlanguage pragmatics. Furthermore, interlanguage pragmatics has been mainly sociolinguistic rather than psycholinguistic, and the development issues haven't got enough attention (Daives \& Tyler, 2005; Kasper \& Rose, 1999). However, their review narrowed down the research scope, selected the research focusing on learning process, and presented them into four groups: cross-sectional studies, longitudinal studies, research about pragmatic transfer, and instructed learning of L2 pragmatics.

Moreover, Neddar (2012) sought to shed light on the relation which existed between discourse, pragmatics, culture and the possibility of integrating these three components in the language classroom. The investigation stressed the need for adopting a purely cross-cultural pragmatic approach to foreign language teaching. This need was paired to the equally important approach based on idealization traditions. Their paper ended up by teasing out two major issues: the problematic relationship between theory and practice and the future perspectives of pragmatics in the act of EFL learning in an era where English has become the dominant linguistic medium of international communication.

In Iranian context, a number of studies have been carried out to explore ILP and its features in SLA contexts. For 
example, Birjandi and Rezaee (2010) developed a Multiple-choice Discourse Completion Test (MDCT) to assess the pragmatic knowledge of Iranian EFL learners in relation to the speech acts of request and apology in EFL classrooms. The development process involved several steps. The first step was exemplar generation. Ninety three Iranian EFL learners at two universities in Tehran were asked to write, in either English or Persian, the situations in which they would request or apologize. The second step was situation likelihood investigation in which the researchers investigated how far the situations suggested by the learners in step one were likely to occur in reality. The third step was scenario generation and initial piloting. For so doing, the generated open ended situations were given to a group of native speakers and nonnative intermediate and advanced learners to respond to the situations. The fourth step included the development of the multiple choices. The responses given in the previous step were used as distracters and correct options for the MDCT items. The fifth step was allocated to the final piloting of the MDCT which confirmed that all the native speakers chose the key as the most appropriate answer to the situations provided.

Moreover, in an attempt to link ILP with language proficiency, Farashaiyan and Tan (2012) sought to investigate the relationship between pragmatic knowledge and language proficiency, that is, whether the learners with different proficiency levels perform differently in a pragmatic test. Secondly, the study aimed at exploring the relationship between gender and language proficiency and pragmatic knowledge. That is, the study examined whether there was any significant difference between the performance of males and females regarding their pragmatic knowledge and language proficiency. One hundred and twenty university students including 60 freshmen and 60 seniors majoring in English Translation from Bandar Abbes Azad University were selected randomly. The participants were placed in the beginning, intermediate and advanced levels based on the results of the proficiency (TOEFL) test. Then, a pragmatic competence test (MDCT) was used to determine the extent of participants' pragmatic knowledge. The calculated data were analyzed through an inferential statistics. The findings of the study obtained through statistical analyses indicated that (a) there was no significant relationship between pragmatic knowledge and language proficiency. In other words, the learners with different proficiency levels did not perform differently in the pragmatic test (b) female participants performed better in pragmatic and proficiency tests.

Regarding the incorporation of ILP in EFL textbooks, Gholami (2015) Pragmatic competence and its development has been a pivotal issue in ELT in the last two decades. This paper explored pragmatic knowledge incorporation into Iranian EFL textbooks. Three high school English books named 'English Book 2, English Book 3 and Learning to Read English for Pre-University Students' were investigated with regard to their use of pragmatic features of English. These three textbooks were analyzed specifically based on speech acts, four politeness strategies, and lexical and syntactic classification. In addition, tense in temporal deixis, adjacency pairs and hesitation marks were analyzed too. The findings demonstrated that little consideration has been given to the incorporation of pragmatic knowledge in developing these materials. This shortcoming may partially account for artificiality of the textbooks. Based on the findings, it was suggested that textbook developers include more pragmatic knowledge into Iranian EFL textbooks to increase on the one hand the authenticity of the textbooks and on the other hand pragmatic knowledge of Iranian EFL students.

In addition, in a more recent investigation, Tajeddin and Malmir (2015) aimed to determine the significant interlanguage pragmatic learning strategies (IPLS) used by high vs. low L2 pragmatic achievers. The study was conducted in two phases. First, they administered a multiple-choice discourse completion test including five common English speech acts to 500 EFL learners. Next, 80 highest and 80 lowest ILP performers were orally interviewed and their answers were audiotaped. The most important interlanguage pragmatic learning strategies were extracted from L2 learners' interviews. The elicited IPLS were arranged based on Cohen's $(2005,2010)$ classification, the findings of the study itself, and an analogy with general language learning strategies (LLS) classification suggested by Oxford (1990). The extracted IPLS were divided into six categories of memory- related, cognitive, social, affective, metacognitive and compensatory IPLS. The high ILP performers used more strategies in all the six categories. Their main conclusion was that the use of more IPLS means a better ILP knowledge of speech acts. Moreover, the most significant implication of the current study was that ILPS need to be taught to L2 learners to enhance their ILP knowledge in general and their speech-act-specific competence in particular.

According to the literature review, a great deal of attention has been paid to interlanguage pragmatics in the literature. However, what attracted the attention of the present researchers was the fact that few studies had so far made attempts to investigate application of interlanguage pragmatic features into translation and interpreting studies. To this aim, since interpretation ability is a significant component of translation students' proficiency and the students were observed to lack the ability to interpret fair enough, exploration of the effects of application of interlanguage pragmatics was felt more than pertinent. Moreover, the literature does not include studies that had taken account of effects of interlanguage pragmatic features on another other abilities than pragmatic knowledge. It also would hopefully fill the present gap in the literature in the sense that not only would it aim to teach pragmatic features to gain other abilities than the pragmatics competence, but also it might open a new door for the transference of interlanguage pragmatics into other fields of study.

The present study was a new one in the field in Iranian context since it offers an interdisciplinary design. In this sense, it would encourage researchers of other translational studies to employ interlanguage pragmatics to their research practice. In other words, it attempted to shift attention from SLA to translational research. It also supports the nature of pragmatics research in the sense that it introduces a new instrument to measure and test individuals' interlanguage pragmatics. Another dimension to the present study was that it is different from the previous ones in the literature since 
it comes up with useful strategies and procedures that can help teachers, professors and language translation instructors to employ pragmatics features so as to create pragmatically competent learners and productive environments.

The present study sought to investigate whether Iranian translation students were successful in comprehending interlanguage pragmatic (ILP) features. Moreover, it tried to figure out whether teaching interlanguage pragmatics proved helpful for the improvement of interpretation ability of Iranian translation students. This study sought to provide answers to the following questions:

1. To what extent BA students of translation use pragmatic features required for interpretation?

2. Do teaching interlanguage pragmatics prove helpful for the improvement of interpretation ability of BA students of translation in an Iranian context?

\section{Method}

\subsection{Design and Setting of the Study}

The study sought to estimate the likelihood of positive effect(s) of application of ILP into SLA translational contexts. The present study employed a quasi-experimental design accordingly considering the fact that sampling was done based on availability not randomly. The present study was conducted in an Iranian context. The participants studied English Translation in Islamic Azad University of Khorasgan, Isfahan, Iran. Moreover, the participants were passing interpretation courses in this university in the academic year 2016-2017.

\subsection{Participants}

The participants of the study comprised of 30 undergraduate students of translation studying at Islamic Azad University, Isfahan (Khorasgan) Branch, with the age range between 18 and 38. Sampling was done based on availability. There were divided into two groups: control and experimental groups, with almost equal number of males and females in each group. Moreover, the students were passing the course of 'interpretation' at the time of the study. They were all EFL students and none of them was an ESL because they had no experience of being in a foreign country for the aim of learning English.

\subsection{Instruments}

\subsubsection{Oxford Placement Test (OPT)}

The Oxford Placement Test (OPT) was used to measure the participants' language proficiency. As a Proficiency test, it is expected to be norm-referenced and is intended to "measure global language abilities" (Brown, 2005, p. 2). One characteristic of a proficiency test, as a norm-referenced test, is that it should produce "scores which fall into a normal distribution" (p. 5), which allows relative interpretations of the test scores in terms of "how each student's performance relates to the performances of all other students" (p. 4). The second characteristic of the test is that "the test must provide scores that form a wide distribution, so that interpretations of the differences among students will be as fair as possible" (p. 8). In other words, a proficiency test tends to test overall general language proficiency. So use was made OPT to make sure about students' homogeneity prior to the application of the treatment. Oxford Placement Test (OPT), consisted of 70 multiple- choice items. It included 20 listening items, 20 reading items, and 30 items related to language use.

\subsubsection{Discourse Completion Test (DCT)}

Discourse Completion Test (DCT) was used to measure participants' interlanguage pragmatics. This was done to investigate the participants' initial interlanguage pragmatic prior to the application of ILP instruction. The choice of DCT was made among other data collection instruments because this test has its advantages. Firstly, in comparison with other data collection instruments, DCTs are easy to use. Secondly, although Cummings (2006) sees DCTs as incapable of depicting real-life interaction, she highly encourage the use of DCT in the field of pragmatics. She also add that one of the strengths of DCTs is their ability to provide rich data in a comparable short period of time. Thirdly, DCTs generate standard responses that probably appear in unplanned discourses and correspond with natural data in the basic formulas and pattern.

Nelson, Carson, Al Batal, and El Bakary (2002) regard DCT as a suitable data collection tool for the field of interlanguage pragmatics. A DCT can be easily used with participants of diverse cultural backgrounds, compared with natural data, which is difficult to control in terms of variables such as status and cultural backgrounds. Kwon (2004) states that DCT can be controlled, and therefore allows for variation in participants' responses, as the status is being embedded in the given situations. This enables participants to know which strategy to use when they have a situation in which the status level differs, whether being lower, equal, or higher. These advantages have led to wide use of DTC in interlanguage pragmatic studies. The DCT used in this study was adapted from Blum-Kulka (1980) and its purpose was to examine interlanguage knowledge. The DCT is a written questionnaire consisting of a number of designed situations used to elicit specific speech acts. Each situation contains a prompt to make it easy for the participants to respond to the situation in writing.

\subsection{Interpretation Pre-test and Post-tests}

To test interpretation ability, the researchers gave the participants an audio file in English and asked them to interpret simultaneously. Obviously the files included interlanguage pragmatic features so as to fulfill the aims of the study. To this aim, a wide range of pragmatic features were incorporated in the pre-test and the post-test, so that the results would have the most reliability. The validity of the two checklists (each with a total scores of 30) which were designed to 
quantify the data on correct use of pragmatic features was determined by two experts with good experiences in teaching interpretation course to BA students of translation in the university.

\subsection{Procedures}

The present study made use of a pre-test and a post-test for the purpose of data collection. Here, the dependent variable was interpretation ability and the independent variable was instruction according to ILP features. Firstly, both the control and the treatment groups were given the pre-test which was in the form of audio files given to participants and recorded interpretations of them received back. Their knowledge of interlanguage ability was quantified according to a researcher-designed checklist which determined to what extent the participants were able to interpret interlanguage pragmatic features.

Secondly, the scores on the checklists were indicators of participants' performances of interlanguage pragmatic knowledge. In this way, at the end of the pre-test 30 scores existed for the participants: 15 score for the control and 15 scores for the treatment group. After the pre-test, the scores were recorded and analyzed to figure out whether both groups are in the same level of interlanguage pragmatic knowledge. This was done to make sure about the homogeneity of the participants. After the treatment, the post-test was administered, which was in fact audio files including features assessing interlanguage pragmatics.

During a two-month period in the semester, the experimental group were presented by the interlanguage pragmatic features (see Appendix) in their interpretation course while the control group was not receiving any instruction concerning interlanguage pragmatics. In other words, the control group was taught through the traditional method of teaching interpretation during the term and the treatment group implicitly got instructions on application of interlanguage pragmatic features in their interpretation tasks.

To analyze the data, a sample independent t-test was run on the scores obtained from the posttests, Using the SPSS, version 20. The coefficients of correlation between the performances of the groups investigated and compared against one another so as to find out whether there existed significant relationship between them at the end of the treatment.

\section{Results}

\subsection{Homogeneity of the Participants' Proficiency Level}

Prior to the application of the treatment it was necessary to evaluate the participants' homogeneity. For this aim, they were given a OPT and scores were analyzed by $t$ test. The results are shown in Table 1 and Table 2.

Table 1. Descriptive Statistics for the Oxford Placement Test

\begin{tabular}{cccccc}
\hline & Group & $\mathrm{N}$ & Mean & $\begin{array}{c}\text { Std. } \\
\text { Deviation }\end{array}$ & Std. Error Mean \\
\hline \multirow{2}{*}{ OPT } & Experimental & 15 & 68.40 & 4.01 & 1.04 \\
& Control & 15 & 67.40 & 2.80 & .72 \\
\hline
\end{tabular}

Table 2. Results of Independent Samples t-test

\begin{tabular}{|c|c|c|c|c|c|c|c|c|c|}
\hline \multicolumn{3}{|c|}{$\begin{array}{c}\text { Levene's Test for Equality of } \\
\text { Variances }\end{array}$} & \multicolumn{7}{|c|}{ T-test for Equality of Means } \\
\hline & & \multirow[t]{2}{*}{ F Sig. } & \multirow[t]{2}{*}{$\mathrm{t}$} & \multirow[t]{2}{*}{$\mathrm{df}$} & \multirow[t]{2}{*}{$\begin{array}{l}\text { Sig. } \\
(2- \\
\text { tailed })\end{array}$} & \multirow[t]{2}{*}{$\begin{array}{c}\text { Mean } \\
\text { Difference }\end{array}$} & \multirow[t]{2}{*}{$\begin{array}{l}\text { Std. Error } \\
\text { Difference }\end{array}$} & \multicolumn{2}{|c|}{$\begin{array}{c}95 \% \\
\text { Confidence } \\
\text { Interval of the } \\
\text { Difference }\end{array}$} \\
\hline & & & & & & & & Lower & Upper \\
\hline \multirow{2}{*}{ OPT } & $\begin{array}{c}\text { Equal } \\
\text { variances } \\
\text { assumed }\end{array}$ & 1.62 .21 & .79 & 28 & .44 & 1.00 & 1.26 & -1.59 & 3.59 \\
\hline & $\begin{array}{c}\text { Equal } \\
\text { variances } \\
\text { not } \\
\text { assumed }\end{array}$ & & .79 & 5.01 & .44 & 1.00 & 1.26 & -1.60 & 3.60 \\
\hline
\end{tabular}

According to Table 2, it is evident that members of both groups were at the same level of proficiency (i.e. advanced). This can be seen in the results obtained from independent samples $t$ test (Sig. $=0.44)$. Sig. value is more than $0.05(\mathrm{p}>$ .05 ) and so there was significant difference between the QOPT scores and so participants are homogeneous in terms of their proficiency level. 
4.2 Descriptive Statistics Before and After the Treatment

Table 3 illustrates the means of scores for both control and treatment groups. As can be seen mean of scores is higher for the treatment (case) group both in the pre-test and the post-test. In what follows, these points are explained and elaborated in more detail.

Table 3. Means of Scores of Pre-test and Post-test

\begin{tabular}{lccc}
\hline Group & & Pre-test & Post-test \\
\hline EC & Mean & 20.13 & 27.33 \\
& N & 15 & 15 \\
& Std. Deviation & 2.29 & 3.921 \\
& Mean & 19.53 & 19.60 \\
CG & N & 15 & 15 \\
& Std. Deviation & 2.32 & 1.91 \\
& Mean & 19.83 & 23.46 \\
Total & N & 30 & 30 \\
& Std. Deviation & 2.29 & 4.967 \\
& & & \\
\hline
\end{tabular}

\subsection{Comparison of Pre-test Results}

As seen in the Table 4, means of pre-test scores were 20.13 for the treatment and 19.53 for the control group. Also, the difference between the means was not significant. So, prior to the application of the treatment, the participants were at the same level of interlanguage pragmatic competence.

Table 4. Means of Pre-test Scores for the Case and Control Groups

\begin{tabular}{llllll}
\hline & Groups & N & Mean & Std. Deviation & Std. Error Mean \\
\hline Pre-test & EG & 15 & 20.1333 & 2.29492 & .59255 \\
& CG & 15 & 19.5333 & 2.32584 & .60053 \\
\hline
\end{tabular}

Groups' performances in the pre-tests have been compared through an independent samples $t$ test whose results are presented in Table 5.

Table 5. The Results of Independent Samples T-test for the Case and Control Groups

\begin{tabular}{|c|c|c|c|c|c|c|c|c|c|}
\hline \multicolumn{4}{|c|}{$\begin{array}{c}\text { Levene's Test for Equality of } \\
\text { Variances }\end{array}$} & \multicolumn{6}{|c|}{ t-test for Equality of Means } \\
\hline & & \multirow[b]{2}{*}{ Sig. } & \multirow[b]{2}{*}{$\mathrm{t}$} & \multirow[b]{2}{*}{$\mathrm{df}$} & \multirow{2}{*}{$\begin{array}{l}\text { Sig. (2- } \\
\text { tailed) }\end{array}$} & \multirow{2}{*}{$\begin{array}{c}\text { Mean } \\
\text { Difference }\end{array}$} & \multirow{2}{*}{$\begin{array}{l}\text { Std. Error } \\
\text { Difference }\end{array}$} & \multicolumn{2}{|c|}{$\begin{array}{l}95 \% \text { Confidence } \\
\text { Interval of the } \\
\text { Difference }\end{array}$} \\
\hline & $\mathrm{F}$ & & & & & & & Lower & Upper \\
\hline \multirow[t]{2}{*}{ Pre-test } & $\begin{array}{l}\text { Equal } \\
\text { variances } .067 \\
\text { assumed }\end{array}$ & .798 & .71 & 28 & .483 & .60 & 84.36 & -1.12 & 2.32 \\
\hline & $\begin{array}{c}\text { Equal } \\
\text { variances } \\
\text { not } \\
\text { assumed }\end{array}$ & & .71 & 27.99 & .483 & .60 & 84.36 & -1.12 & 2.32 \\
\hline
\end{tabular}


According to Table 5, the value Sig. $=0.483(\mathrm{p}>0.05)$ indicates that, in the pre-test, the groups' performances were not different because no significant difference was seen. So, the two groups had similar performances. Moreover, with regard to the mean of scores obtained from the pre-test, it can be suggested that the first hypothesis, that is 'Iranian MA students of translation are not successful in comprehending pragmatic features', it can be claimed that this hypothesis stands true and it is not rejected. So participants did not have a reasonable performance on the pre-test.

4.4 Comparison of Post-test Results

ANCOVA was run on the scores obtained from both the pre-test and the post-test. Results are presented in Table 6 . Table 6 illustrates means of scores for the two groups' scores in the post-test.

Table 6. Means of Post-test Scores for the Two Groups

\begin{tabular}{cccc}
\hline Group & Mean & Std. Deviation & N \\
\hline Experimental & 27.33 & 3.92 & 15 \\
Control & 19.60 & 1.91 & 15 \\
Total & 23.46 & 4.96 & 30 \\
\hline
\end{tabular}

Additionally, results of ANCOVA are also shown in the following parts, investigating the effect of the treatment. Table 7 shows the results obtained from the ANCOVA tests.

Table 7. Results of ANCOVA

\begin{tabular}{clllll}
\hline Source & Type III Sum of Squares & df & Mean Square & F & Sig. \\
\hline Corrected Model & 482.76 & 2 & 241.38 & 28.008 & .000 \\
Intercept & 73.27 & 1 & 73.277 & 8.5 & .007 \\
Pre-test & 34.23 & 1 & 34.235 & 3.97 & .056 \\
Group & 408.46 & 1 & 408.46 & 47.39 & .000 \\
Error & 232.69 & 27 & 8.61 & & \\
Total & 17236.00 & 30 & & & \\
Corrected & 715.46 & 29 & & & \\
Total & & & & & \\
\hline
\end{tabular}

More detailed results of the effect of treatment are illustrated in Table 7. This table depicts results of ANCOVA. In ANCOVA Test, scores of the post-test are the response variable and scores obtained from the pre-test are the covariate (the variable that is controlled). As it is observed in Table 7, Sig. $=.056$ which is a value for the covariate variable (pretest scores) is higher than $0.05(\mathrm{p}>0.05)$ and this indicates that scores obtained from the post-tests were independent of this variable and so pre-test had no interference with the experiment. More importantly, Sig. $=0.000$ for the groups is lower than 0.05 and this means that there exists a significant difference between the performances of the control and the treatment groups.

\section{Discussion}

The present study was an attempt to figure whether incorporation of ILP features could have positive impacts on the improvement of translational students' interpretation ability. Analyses were carried out to investigate the issue by dividing the participants into two control and treatment groups where the treatment group was provided with ILP feature during the treatment while the control were treated with no incorporation of ILP features. The results revealed that participants were homogeneous in terms of their proficiency level. So, the participants were all at the same level of proficiency and application of the treatment was proper.

\subsection{Addressing Research Question One}

To What Extent are Translation Students Successful in Comprehending Pragmatic Features? The results related to the ability of translation students' comprehension of ILP feature showed that all the participants were the same in terms of using interlanguage pragmatic features. However, in comparison with their ability in using ILP feature after the treatment, means of both groups indicated that their ability was lower and they were not good enough in using the ILP features.

In line with results obtained in the present study, findings of Farashaiyan et al. (2014) indicated that instructors made use of implicit instruction of pragmatic rules with inductive approach while they did not use explicit teaching of interlanguage pragmatic features. This finding can be said to be in line with those of the present study since both situations lack fair distribution and presentation of explicit ILP features. 
Moreover, supporting the importance of teaching pragmatic knowledge to Chinese EFL learners in classrooms Jianda (2002) concluded with the suggestion that EFL teachers should teach pragmatic knowledge in class and include interlanguage pragmatic knowledge in large-scale tests. This is also in agreement with conclusion obtained in the present study. In a similar vein, Rahimi Domakani and Felfelian and (2012) noticed that Iranian EFL context lacked a fair application of ILP features and that this is a problem which needs to be eradicated.

The same notion of lack of application of ILP features in an Iranian context was supported by Mirzaei and Esmaeili (2013) who came to the conclusion that learners' language proficiency did not play any role in incorporating pragmatic instruction into the classroom. Nevertheless, they concluded that explicit instruction could facilitate the development of pragmatically appropriate use of language.

\subsection{Addressing Research Question Two}

Do Interlanguage Pragmatics Teaching Prove Helpful for the Improvement of Interpretation Ability of Iranian Translation Students? The results obtained from both the treatment and the control groups after running ANCOVA were obtained. It was revealed that the treatment group outperformed the control group which is an indicative of effectively of the treatment. So, application of ILP features into interpretation courses was proved efficient for the participants of the present study. Moreover, members of the control group for whom no ILP feature was incorporated did not show any improvement in their ability to use ILP features while interpreting. In what follows, a comparison of results of other studies is made with that in the present finding.

The effectively of instruction of ILP features which was obtained here is in agreement with that of Khodareza and Lotfi (2013) who concluded that formal instruction of pragmatic knowledge play a significant role in the enhancement of Iranian intermediate EFL learners' interpretation of speech acts (ILP). Further, they concluded that formal instruction of pragmatic knowledge plays a significant role in the enhancement of Iranian intermediate EFL learners' use of speech acts' was supported. Also, the same relationship is true for Esmaeili and Mirzaei (2013) who concluded the existence of significant gains made by the experimental groups receiving instruction support the claim recently made by instructional pragmatics that explicit instruction does facilitate the development of pragmatically appropriate use of language.

In addition to this, Gholami's conclusions (2015) are in line with those of the present study. He came to the conclusion that pragmatic competence and its development has been a pivotal issue in ELT in the last two decades. Moreover, the findings demonstrated that little consideration has been given to the incorporation of pragmatic knowledge in developing these materials.

Tajeddin and Malmir (2015) also reported that the use of more IPLS means a better ILP knowledge of speech acts. Moreover, the most significant implication of the current study was that ILPS need to be taught to L2 learners to enhance their speech-act-specific competence in particular and their ILP knowledge in general.

In contrary to the present study, Farashaiyan and Tan (2012) contended that there was no significant relationship between language proficiency and pragmatic knowledge. In other words, their experiment revealed that the learners with different proficiency levels did not perform differently in the pragmatic test and that female participants performed better in pragmatic and proficiency tests.

\section{Conclusion}

The present study investigated the application and effectively of ILP features within a university context, which is interpretation course for Iranian students of translation. As presented in the above sections, it was revealed that ILP features are lacking in many educational contexts, including that of the present study which was a university context. First hypothesis concerned the presence and application of ILP features in interpretation classes. The first hypothesis which was read as "translation students are not successful in comprehending pragmatic features" was not rejected since the same was seen in interpretation classes. So the hypothesis was not annulled and the answer to the first research question could be that in the present interpretation class in Iranian context, translational students are not provided with the ILP feature that are required to be applied into the courses.

In this sense, if ILP features are taken into interpretation courses, undoubtedly students' interpretations would be improved. This is because the knowledge the ILP features is very important in comprehending the situation and then translating it into the mother tongue. This can be used by university professors of Translation courses when teaching interpretation courses. Therefore, the study revealed that more attention needs to be paid to whether students are provided with a set of necessary ILP features or not.

Secondly, the second research hypothesis which was "teaching interlanguage pragmatics features does not prove helpful for the improvement of interpretation ability of Iranian translation students" was rejected since the opposite was proved to be true. Results indicated that ILP features were proved very effective for Iranian students of interpretation. In this sense, university professors can pay attention to this finding and, where required, they can incorporate ILP features into their courses so as to make attempts to render a more effective learning and teaching environment. This conclusion was already approved in all previous studies mentioned above.

Thirdly, the findings of the present study have shed light on the usefulness of interlanguage pragmatic features in educational contexts. Any educational context concerned with the improvement of pragmatic awareness in its learners can take measures to incorporate these elements into its curriculum, syllabuses or textbooks so as to render better results. 
Fourthly, in translational studies, this study can be a helpful one since it make a different analysis of one part of the students' competency, which is interlanguage pragmatic competence. In this sense, the study made a new attempt in the translational field since it tried to transfer an issue of the field of SLA into the field of translation. This was a novel job which can be named as an interdisciplinary study. So, this can gain more importance when it can be the first of many future studies investigating one issue of SLA within translational studies. In so doing, field of translational studies is potential of embracing a number of researches borrowed from other fields of study and, in this way, mitigate against the students' drawbacks and provide better learning environments.

\section{References}

Birjandi, P. \& Rezaei, S. (2010). Developing a multiple-choice discourse completion test of interlanguage pragmatics for Iranian EFL learners. ILI Language Teaching Journal (Special Issue: Proceedings of the First Conference on ELT in the Islamic World, 6(1, 2), 43-58.

Blum-Kulka, S., (1980). Learning how to say what you mean in a second language: A study of speech act performance of learners of Hebrew as a second language. Applied Linguistics, 3, $29-59$.

Brown, J. D. (2005). Testing in language programs. New York, NY: McGraw-Hill.

Cai, L., \& Wang, Y. (2013). Interlanguage pragmatics in SLA. Theory and Practice in Language Studies, 3(1), 142147.

Cohen, A. D. (2005). Strategies for learning and performing L2 speech acts. Intercultural Pragmatics, 2(3), $275-301$.

Cohen, A. D. (2010). Teaching and learning pragmatics: Where language and culture meet. Routledge.

Farashaiyan, A., \& Tan, K. H. (2012). On the relationship between pragmatic knowledge and language proficiency among Iranian male and female undergraduate EFL learners. 3L; Language, Linguistics and Literature, The Southeast Asian Journal of English Language Studies, 18(1), 33-46.

Farashaiyan, A., Tan, K. H., \& Subakir, M. (2014). An investigation of Iranian instructors' methods and techniques in teaching interlanguage pragmatics. Procedia-Social and Behavioral Sciences, 118, 61-67.

Gholami, J. (2015). Is there room for pragmatic knowledge in English books in Iranian high schools? English Language Teaching, 8(4), 39.

Huang, C. C. (2010). Other-repetition in Mandarin child language: A discourse-pragmatic perspective. Journal of Pragmatics, 42(3), 825-839.

Jianda, L. (2002). Assessing EFL learners' interlanguage pragmatic knowledge: Implications for testers and teachers. Reflections on English language teaching, 5(1), 1-22.

Jianda, L. (2007). Developing a pragmatics test for Chinese EFL learners. Language Testing, 24(3), 391-415.

Kasper, G. (1992). Developmental issues in interlanguage pragmatics. Studies in Second Language Acquisition, 18(02), 149-169.

Kasper, G., \& Blum-Kulka, S. (1993). Interlanguage pragmatics: An introduction. In G. Kasper, and S. Blum-Kulka (Eds.), Interlanguage pragmatics (pp.3-18). New York: Oxford University Press.

Kasper, G., \& Rose, K. R. (1999). An exploratory cross-sectional study of interlanguage pragmatic development. Studies in Second Language Acquisition, 22(1), 27-67.

Kasper, G., \& Rose, K. R. (2002). Pragmatic development in a second language. Oxford: Blackwell.

Khodareza, M., Lotfi A, R. (2013). Interlanguage pragmatic development: The effect of formal instruction on Iranian learners' interpretation and use of speech act of apology. Asian Journal of Social Sciences and Humanities, 2(2), 99104.

Kwon, J., (2004). Expressing refusals in Korean and in American English. Multilingua - Journal of Cross-Cultural and Interlanguage Communication, 23(4), 339-364.

Matsuda, M. (1999). Interlanguage pragmatics: What can it offer to language teachers? The CATESOL Journal, 11(1), 39-59.

Mirzaee, A., \& Esmaeili, M. (2013). The effects of planned instruction on Iranian L2 learners' interlanguage pragmatic development. International Journal of Society, Culture \& Language, 1(1), 89-100.

Neddar, B. A. (2012). Short notes on discourse, interlanguage pragmatics and EFL teaching: where do we stand? Procedia-Social and Behavioral Sciences, 46, 5687-5692.

Nelson, G.L., Carson, J., Al Batal, M., \& El Bakary, W. (2002). Cross-cultural pragmatics: strategy use in Egyptian Arabic and American English refusals. Applied Linguistics, 23(2), 163-189.

Oxford, R. L. (1990). Language learning strategies: What every teacher should know. Newbury House Publishers.

Rahimi Domakani, M., \& Felfelian, S. (2012). L2 learner interlanguage pragmatic development within ZPD activated proximal context. Paper presented at the First Conference on Interdisciplinary Approaches to Language Learning and Teaching, Mashhad, Iran. 
Rezaei, R, Chiew, T. K. \& Lee S. P. (2014). A review on E-business Interoperability Frameworks. Journal of Systems and Software, 93, 199-216.

Selinker, L. (1972). Interlanguage. IRAL-International Review of Applied Linguistics in Language Teaching, 10(1-4), 209-232.

Tajeddin, Z., \& Malmir, A. (2015). The construct of interlanguage pragmatic learning strategies: investigating preferences of high vs. low pragmatic performers. Journal of Teaching Language Skills, 6(4), 153-180.

Vygotsky, L. (1978). Interaction between learning and development. Readings on the Development of Children, 23(3), 34-40. 